\title{
A Study of the Status and Marketing Strategies for Qingdao Shibei Fitness Clubs
}

\author{
Mingxia Wang ${ }^{1}$ \\ ${ }^{1}$ School of Physical Education, Qingdao University of Science and Technology, Qingdao, China \\ Correspondence: Mingxia Wang, School of Physical Education, Qingdao University of Science and Technology, \\ No.99 Laoshan District, Qingdao 266061, China. E-mail: wmx7172@sina.com
}

Received: August 16, 2016

doi:10.5539/ass.v12n9p244
Accepted: August 22, $2016 \quad$ Online Published: August 26, 2016

URL: http://dx.doi.org/10.5539/ass.v12n9p244

\begin{abstract}
As the rapid development of domestic economy, the new situation springs up like mushrooms in Qingdao fitness market, the study takes the most representative 10 fitness clubs as the main objects, relying on interview methods, questionnaire ways etc. to analyze the problems of product services and managements, price positions, the siting of the fitness clubs, marketing tools and other factors. We deeply discussed the existing problems of the current Qingdao commercial fitness clubs markets, and presented more reasonable marketing strategies in order to promote the development of Qingdao fitness clubs.
\end{abstract}

Keywords: fitness clubs, status, marketing strategy

\section{Preface}

Since the reform and opening, as the rapid development of social economy, people's lives standard have a greatly improvement. Urban and rural residents generally begin to concern and pay more attention to their life qualities, which caused the domestic fitness industries' development growing vigorously. China's fitness industry is coming into an unprecedented era of great development. Fitness developments around the country present a splendid sight, and the rising of fitness clubs springs up like mushrooms that they all spare no effort to show their advantages to attract customers by enlarging propaganda work, which formed a fierce competition in fitness market. Facing with this phenomenon, a study for fitness marketing strategy is very necessary and urgent. Fitness marketing strategy is to reach the economic and social object to provide effective products and services to satisfy the customers and make the clubs earn profits through a process including analysis, planning, action, feedback and control which based on the demand in fitness consumption to coordinate various kinds of fitness economic activities. Marketing strategy is a social and management process that individual and mass aim to meet their demands and desires by creating and exchanging with others' products and values. Fitness marketing strategy is a very important section to develop fitness industry and earn economic benefits. The study for fitness marketing strategy will undoubtedly have the vital significance to the development of China's fitness industry.

\section{The Status of Qingdao Shibei Fitness Clubs}

\subsection{Management Actuality}

A unified statement said that there are about 30 gymnasiums reached a certain scale in Shibei district, Qingdao City, some other gyms such as small scale Taekwondo Gymnasiums and fitness centers are not included. The main commercial fitness clubs including Yingjiduo, Chenguangshanse, 52, Chinese style, Yahai, Asia (Yanan Road), Qingdao Taige, Qingdao Maliqi Yoga, Tingfeng Yoga and New Space Time fitness clubs.

\subsubsection{The Commercial Fitness Clubs in Shibei District, Qingdao City Are Divided into the Following Levels}

a) High-end fitness clubs (The investment are more than 2,000 RMB) are absent, because the upfront costs are so big, and the recovery of funds is so slow, certainly the price of annual card generally cost more $3000 \mathrm{RMB}$ is also the reason why the high-end clubs cannot be accepted.

b) The middle to high class fitness clubs always have magnificent decorations, completed facilities, various services, fitness, entertainments, Beauty and bathing.

Customers can choose the training items by themselves, instructors are careful and patient, and the staff will provide good services for every customer, of course, the annual card of this kind of clubs will cost you about 


\section{0-3000 RMB.}

There is a large number of these clubs that they were aimed specially at higher income people, although they need a high investment, the recovery of funds is faster.

c) The medium-grade fitness clubs is mainly to fitness training.

According to the different situations, they open different fitness projects. Certainly, the items and time are fixed, shower equipment is available. The cost of these clubs will be 50-150 RMB per month, annual card may be 400-750 RMB.

d) The gyms with poor conditions usually have only one room, one stereo equipment, 1-2 inductors, some dumbbells and barbells. They are set up at the street, people spend about 20-50 RMB per month can go have a fitness time, the annual card certainly cannot be expensive, 100-350 RMB will help you to have a full year time to exercise.

These clubs are aimed at residents to do some exercises in their free time.

\subsubsection{The Specific Circumstances of VIPs of Commercial Fitness Clubs in Shibei Distric, Qingdao City}

In present market of commercial fitness clubs in Shibei district, Qingdao city, the VIPs aged 25-45 have reached $89 \%$, moreover, aged 30-35 and aged 35-40 have arrived at 57\%

Based on the survey of the VIPs' occupational information on Qingdao fitness clubs, the current VIPs in fitness clubs are based on company employees, freelancers, and enterprise administrators. These three kinds of people occupied more than $60 \%$. So, if you want to build a new fitness club, you need to refer to the above statistics and pay more attention to these factors when you decide to select the site.

According to the statistics, the VIPs of commercial fitness clubs in Shibei district, Qingdao city whose income are more than $3000 \mathrm{RMB}$ have occupies $42 \%$ (6000 RMB per month is $9 \%$, 4000-6000 RMB per month is $11 \%$, $3000-4000$ per month is $22 \%$ ), and the percentage of the VIPs whose income are $2000-3000$ per month is $34 \%$. We can know from this that as the improvement to people's consumption concepts and the increasing numbers of fitness clubs in Qingdao city, people pay more attention to their health and invest more in fitness. The status of fitness groups is gradually becoming top, middle and low-grade can coexist instead of only high and mid-grade people.

\subsection{The Status of Qingdao Shibei Fitness Clubs}

\subsubsection{Product Services and Managements}

Judging from the situation of survey, the management functions of the fitness clubs in Shibei district, Qingdao City are two kinds: profit-oriented projects and matching projects. There are 20 kinds in the former, including Pilates, Aerobic boxing, workout on fitness equipment, street dancing, Yoga, physique, shaping, Latin, taekwondo, Adult Ballet, aerobic exercises, spinning, swimming, billiard, tennis etc. The latter includes beauty, sauna, pedicure, table tennis, clothing sales and so on.

The differences among clubs are not obvious. However, high-end clubs have completed and well equipped Fitness equipment, and the kinds of body-building items are abundant, rigorous and orderly management as well can be their service features. Middle and low grade clubs have fewer items; bad environments undoubtedly become their weaknesses to attract customers. As for middle and small scale clubs, they are unable to keep pace with Client Reviews, health consultations and evaluations, exercise prescriptions and other service items, some special exercise projects such as taekwondo and rock climbing will not be explored.

Administrators in clubs can be divided into three kinds: executive officers (investors), coaches and ordinary equipment maintenance personnel.

There are three clubs have more than 10,000 VIPs, five clubs have 3000-6000 VIPs, and other clubs have 800-1500 VIPs. More than $90 \%$ clubs build personal profiles for VIPs, and they hire full time accountants to help to Manage General Ledger; furthermore, $70 \%$ clubs organize regular trainings for coaches. The graduates from physical education institutes or departments, retired athletes or dancers, and well-known fitness enthusiast make up the three sources for fitness instructors. Among them, male is $55.2 \%$, female is $44.8 \%$, aged $21-35$ is $88.6 \%$, and these are basically reasonable gender ratios and age structures. What is more, $90.6 \%$ instructors have fitness instructors' qualification and grade certificates, and $90.7 \%$ trainees speak highly of instructors' services.

\subsubsection{Price Position and Customer Control}

The present operational fitness clubs in Shibei district, Qingdao city usually adopt a method that cost pricing combined with demand pricing, which is entire market. Due to there is not a relatively unified standard to pricing 
decisions, the prices of different grades of fitness clubs are quite different in various payment methods. For example, the single ticket for fitness in Chinese style and other high-end operational fitness clubs is between 40 to 60 RMB; trainees' month card are 418 RMB, VIPs' are 368 RMB; VIPs' season card are 1200 RMB; VIPs' half-a-year card are 2400 RMB; VIPs' annual card are 4500 RMB. The single ticket for fitness in middle and low grade clubs is $2 / 3$ of the price of high-end clubs. The pure income is between 1800 to 2500 RMB per month, only $25 \%$ clubs' pure income can be more than $30,000 \mathrm{RMB}$; it is really not an industry as profiteering as people think.

Most of those for-profit fitness clubs utilize basically sound membership systems to realize customer control, such as Gold Members, Silver Members, and Ordinary Members. Odd customers although come to these clubs for bodybuilding, they are not the main consumers.

\subsubsection{The Siting of Clubs}

Through the status analysis for the regional distributions on the surveyed Qingdao fitness clubs we can know that the distributions of Qingdao operational fitness clubs are very uneven, and the coverage ratios in popular residential areas are not high. As many as 10 clubs' headquarters are centered on the residential areas on Yanan Road, Taidong Eighth Road, Hefei Road etc., and these clubs occupied $92.3 \%$ in the surveyed clubs. Only few high and mid grade clubs situated in Qingdao city center Hong Kong Road that has beautiful environments, and these clubs had begun to take shape at 150 square kilometers' floor spaces.

\subsubsection{Marketing Method}

The marketing methods of fitness clubs are not good enough in the degree of modernization in Shibei district, Qingdao city. These following two sites will carry out explanations:

First, the only way to realize customer control is to regulate the fluctuations for ticket prices;

Second, they utilize the advantages of the ticket discount to attract customers to get cards. Short-term Consumer Cards like month cards, annual cards; VIP cards as Gold cards, Silver cards etc.

Nevertheless, these clubs ignored the innovative reforms of product qualities in new, different, funny and happy, and they also omitted the personalized services. Because of the absent of systematic understandings in fitness marketing strategies, it resulted in the current vicious competition, such as discount, vicious price reduction and poaching of customers. These clubs just delivered simple pamphlets and posted store advertising, without conducting vigorous propaganda for health knowledge and the importance of fitness in mainstream media, it resulted in the popular consumers failed to have enough recognitions on fitness market. $87.6 \%$ of the ordinary citizens do not know more information about fitness market, $62.6 \%$ of the ordinary citizens think of that the fitness market is an entertainment for high-salaried stratum, which is far away from them.

\section{Analysis of the Existing Problems in Fitness Clubs in Shibei District, Qingdao City}

\subsection{Spotty Qualities of Fitness Coaches}

Fitness coaches in fitness clubs exist some questions as follow: uneven teaching levels, uneven comprehensive self-qualities, and irregular systems of professional skill identifications. Therefore, the management for fitness coaches is becoming a very important and troublesome problem during the staff management in clubs.

According to a crude statistics, only $45 \%$ of the coaches are holding authentication certificates that awarded by nation or province authority certificate institutes in the present Qingdao fitness marketing. Many fitness coaches have low degrees of education, most of them are Short-cycle Courses and under, and there are only $26.7 \%$ coaches are College graduated or above. Among them, the coaches graduated from PE majors occupied $46 \%$ of all, especially there are only $39 \%$ coaches have been trained professionally. Discovered through investigation, coaches of bodybuilding exercises have higher degrees of education than others, because they are mainly from students or teachers in physical culture institutes and departments. However, the coaches of other items such as Yoga, Pilates and workout on fitness equipment are mainly from the previous trainees, their comprehensive self qualities and Professional Dedication Spirits both need improving.

\subsection{Large Liquidity of Membership Consultant}

The management for membership consultant is facing a biggish difficulty in present Qingdao fitness clubs, the large liquidity of membership consultant is the major reason. On a field study, VIPs often complained about that their membership consultant changed so frequently that it cannot work for helping them to do fitness activities. We need to pay attention to that the reason why the membership consultant appears such a large liquidity is some managers take no account of consultants, and they make no account of fostering talent. Inadequate salary and management system also caused the leaving of membership consultants. If the clubs want to have a long-term 
development, some high qualified membership consultants are quite necessary, because they are the mainstays and core members for clubs.

\subsection{Severe Customer Loss}

After visiting fitness clubs, we reached a conclusion based on the collected statistics and on-the-spot interviews that VIPs generally give unsatisfied evaluations to fitness clubs' after-sales services. Large numbers of VIPs indicate that they will not buy fitness cards any more once the cards expired, and they are very dissatisfied and disappointed with the after-sales services, because of inadequate internal service systems and operation mechanisms. They think the fitness clubs' service attitudes reduce greatly after getting cards. For the present Qingdao Shibei Fitness clubs, if they do not improve this in time, it will result in that customers' loyalties decrease, old VIPs lose severely and the fitness clubs will run into troubles. So, if the situation of bankrupt occurs to one clubs, it will cause fitness industry turmoil in the entire Shibei districts, even the whole city.

\subsection{The Price War}

Many Qingdao fitness clubs always commit a mistake in business process is blind depreciation, which give rise to the price war become increasingly fierce in fitness market.

In order to quickly recoup the costs or enlarge their market shares, some clubs utilize dirt cheap price to attract customers without taking into account of the capacities of clubs, the cost of investment, the monthly expenses for keeping operation and the feeling of old VIPs. This phenomenon disrupts the entire fitness market, although it may definitely earn some money in a short time, the accompanying negative effects will be difficulties for further running. A short-term rapid expansion of members will cause the spaces and equipment far from enough, and customers' satisfactions will decrease even to lose members, and bankruptcies may occur to weak clubs, all of these will reduce the reputation of Qingdao fitness clubs.

\section{The Marketing Strategies of Fitness Clubs in Shibei District, Qingdao City}

\subsection{Serve Customers by Heart}

In terms of the essences of clubs, it is very important to develop clients; what's more, because customers' stabilities are essential to the long-term stabilities of clubs' sources of revenue, doing good jobs on services are particularly important. Clubs need to improve their service levels to satisfy customers in business process. Serving customers by heart will be the only way to retain them.

Whatever old VIPs or new members, clubs should do good follow-ups on after-sales services. Certainly, more alternative privileges can be launched for old VIPs, which may change new members into registered clients. If clubs improve the old VIPs' loyalties, they retain the foremost fortune. Have a deep understanding of the reason why losing customers can help the clubs to implement total services quality control, improve their service management, establish customers' databases and create consumers' satisfaction systems. Thereby they can set effective management policies as follow:

a) Service commitments: Serve customers by heart and abandon ambiguous concepts. Particularly doing good jobs on coordination between sales and after-sales in case the promise made by salesmen cannot be realized, otherwise, it may bring bad influence to clubs.

b) Consumption combination: Club's price systems should be plentiful as far as possible, and provide variable consumption combinations for customers, such as control the time, limit the numbers and confine the grade of members, to attract more customers to become VIPs by utilizing diversified consumption combinations.

c) Detail services: Serve customers by soul. Clubs must record the customers' profiles as much as possible and require the front-line services have a detailed grasp on VIPs' information, in order to make clients feel they enjoy the one-to-one service. For example, clubs can give birthday blessings and little presents to customers during their birthday.

d) Extended services: A very important functions clubs have is "social function". Therefore, in view of the current customers do not have a strong sense of this, clubs can regularly implement different forms of sustainable and business entertainment theme activities.

e) Set up fitness clubs alliance organizations: Clubs should be cautious about "price war". If necessary, clubs can set up Qingdao fitness clubs association or alliance organizations to periodically communicate with other clubs. The market needs value war not price war.

Internal improvements are essential to value war, clubs need to use efficient management methods to improve staff's qualities, increase the technological content of products and promote the value of products. As sayings 
goes, improvement needs change, but perfection must always change. So, survival of the fittest makes clubs must provide continuous innovations and move with the times.

\subsection{Improve the Quality of Products and Establish Brand Recognition}

Further increasing the training strength on faculties, and ensure the "new, different, beauty and funny" in service items; reasonably arrange the members' training processes, and keep a "clear, elegant, clean and beautiful" fitness environment for customers. Certainly, clubs also need to invite dieticians for customers to draw up reasonable meal plans and scientific exercise prescriptions, in order to ensure the exercising effects and the recovery qualities after fitness. In terms of marketing psychology, new consumers will be attracted to clubs by their reputations as scenic spots, consequently say, fitness clubs can improve reputations and brand awareness by subscribing to the hope projects and supporting green and environmental protections.

\subsection{Based on High-end Consumers, and Cover the Mass Consumptions Areas}

Because the siting of the fitness clubs is an important guarantee to customer sources, clubs must give consideration to high-end consumers and mass consumers. Several principles should be paid more attentions to:

Convenient principle. Clubs need to locate in high-end consumptions areas, and mass consumers can have convenient transportations to reach clubs.

Green and environmental protection principle. In today, advocating green environment is becoming the main vocal, and then people think lots of the external natural environments of clubs. Whether the environment is good or not will directly influence customers' interests and exercising effects. At present, the time is ripe for taking advantageous positions and establishing leaders' images.

Network coverage principle. Networked trading modes can maximize the economic benefits and also maximize the coverage of customer sources.

\subsection{Enlarging Propaganda Work in Mainstream Media}

Clubs must do more work on Qingdao mainstream media (QTV, Qingdao life-line, Qingdao Morning News, Peninsula City News and Living Qingdao) to conduct vigorous propaganda. Likewise, building performance teams to show on Qingdao Marine Festival, Qingdao International Beer Festival and any other large-scale activities will effectively boost the potential market.

\subsection{Seek Coordination from the Government, and Support to Build a Harmonious Society}

In today, our government advocates to build a harmonious society, clubs can respond to the call to implement physique monitoring and fitness consulting for residents. Not only do give back to society, but also propagandize their clubs.

\section{Conclusions}

At present, domestic residents' market requirement levels for fitness clubs are very low, in addition, the front-end investment and the operating costs are commonly high, it causes that fitness is only enjoyed by high-end consumers. Whereas, as the economy develops and the rapid increase in the personal incomes, Qingdao fitness market will be larger and larger, the fitness industry will be understood by investors sooner or later. Although the future development of fitness clubs must be surrounded by opportunities and fierce competitions, how to reduce costs and enlarge market will be an urgent strategic problem to be solved.

\section{References}

Chen, X. (2004). Rational thinking for community physical facilities' building. Anhui sports science and technology, 25(1), 64-66.

Feng, H. (2008). A study for China's local government social sports policy, (6). Beijing Sports University Press.

Ge, Z. (2007). Rational thinking for enhancing community physical facilities' building. Journal of Qingdao communist party school Qingdao administration institute, (5), 83-85.

Guo, M. (2001). Promoting $21^{\text {st }}$ century national fitness to a new stage. Sports literature and history, (1), 4-7.

Li, X., \& Su, M. (2008). Introduction for national fitness, (6). Higher education Press.

Liu, F. (2005). Policy of sustainable development for ecological sports tourism. Journal of Shenyang Institute of Physical Education, 2(1), 17-19.

Snyder, E. E., \& Spreitzer, E. A. (1973). Family influence and involvement in sports. Research Quarterly, 44, 249-255. 
Stevenson, C. L. (1975). Socialization effects of participation in sports: A critical review of research. Research Quarterly, 46, 267-273.

The state council of China. (1995, June 20). Outline of the nationwide body-building plan.

\section{Copyrights}

Copyright for this article is retained by the author(s), with first publication rights granted to the journal.

This is an open-access article distributed under the terms and conditions of the Creative Commons Attribution license (http://creativecommons.org/licenses/by/4.0/) 